\title{
Proximity to maternity services and stillbirth risk
}

\author{
Louise Parker, Heather O Dickinson, Tony Morton-Jones
}

\begin{abstract}
A study of all 77995 live births and 1234 stillbirths to mothers living in West Cumbria from 1950 to 1989 found no significant increase in stillbirth risk with distance of mother's residence from the first or second nearest maternity services, after allowing for year of birth, father's social class, and birth order.
\end{abstract}

(Arch Dis Child Fetal Neonatal Ed 2000;82:F167-F168)

Keywords: stillbirth risk; maternity services; epidemiology

It is known that, in developing countries, distance from hospital is a major risk factor for both maternal and perinatal mortality. ${ }^{1}$ However, even in England and Wales, residential proximity to hospitals can be an important determinant of health outcome as demonstrated by a recent study which showed an increasing risk of death from asthma with increasing distance from hospital. ${ }^{2}$

Cumbria is a predominantly rural county with several isolated settlements from which travel to hospitals, especially in the 1950s, would have been difficult and arduous. West Cumbria contains the Sellafield nuclear reprocessing plant and there has been public concern that it may have adverse effects on the health of those living in its vicinity. Dummer et $a l^{\beta}$ investigated whether proximity to Sellafield increased the risk of stillbirth in the resident population, but found no evidence to support this. Nevertheless, after allowing for factors known to influence stillbirth rates, they found spatial heterogeneity in stillbirth risk in Cumbria, in particular an increased risk between 10 and $15 \mathrm{~km}$ north west of Sellafield during 1950-59. ${ }^{3}$ The present study uses an additive isotonic regression model to investigate whether this geographical heterogeneity could be explained by an increase in risk of stillbirth with increasing distance of mother's residence from the first and second nearest maternity services within West Cumbria during 1950-89.

Department of Child Health, University of Newcastle, Royal Victoria Infirmary, Queen Victoria Road, Newcastle upon Tyne NE1 4LP, UK

L Parker

H O Dickinson

Department of

Mathematics and

Statistics, University of

Lancaster, Lancaster

LA1 4YF, UK

T Morton-Jones

Correspondence to:

Dr Dickinson

email: heather.dickinson@

ncl.ac.uk

Accepted 31 July 1999 erence for $0.7 \%$ of the births, and social class was not known for $0.3 \%$ of live births and $1.2 \%$ of stillbirths; these births were omitted from the study.

West Cumbria is a predominantly rural area, bounded by the sea on the west and mountains on the east, with most settlements situated on a coastal plain. Mothers in the area were referred to maternity services in three towns on the coast and to other services outside West Cumbria. Locations and time periods of operation of the 16 units offering maternity services to the population of West Cumbria over this period were ascertained. These comprised: four district general hospitals open during 1950-89, 1950-64, 1964-89, and 1984-89; three general hospitals open during 1958-80,

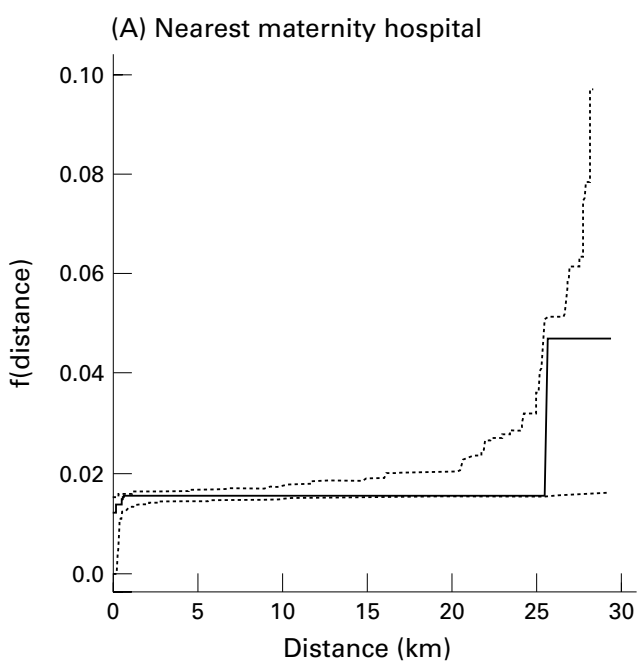

(B) Second nearest maternity hospital

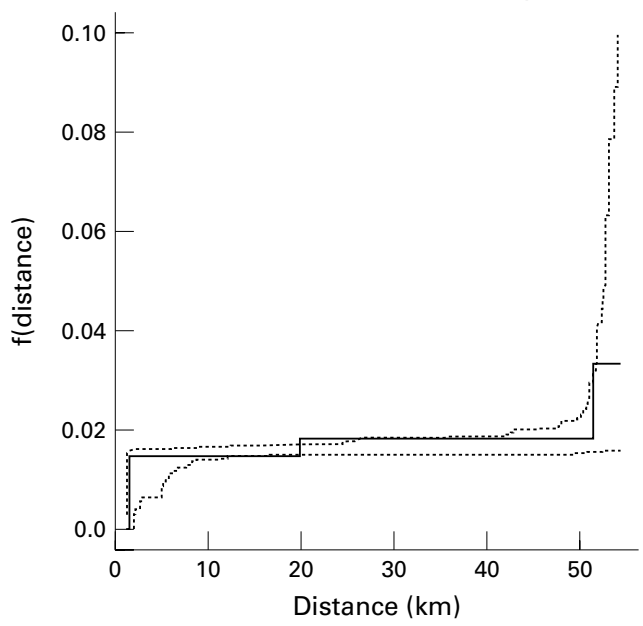

Figure 1 Isotonic regression functions (solid lines) and $95 \%$ tolerance bands (dotted line), adjusted for year of birth, social class, and birth order, showing probability of stillbirth by distance from $(A)$ nearest and $(B)$ second nearest maternity hospitals. 
1960-77, and 1974-84; three cottage hospitals open during 1950-89, 1950-64, and 1951-68; four maternity hospitals open during 1950-89, 1950-84, 1960-89, and 1974-89; and two maternity homes open during 1950-73 and 1950-68. The median distance of mother's domicile from a maternity unit was $6 \mathrm{~km}, 3 \mathrm{~km}$, and $10 \mathrm{~km}$ during 1950-57, 1958-80, and 1981-89 respectively, while the range was $0-25$ $\mathrm{km}$ in the earlier time periods and $0-29 \mathrm{~km}$ in the later time period.

ANALYSIS

The distances of the mother's residence from the first and second nearest maternity services were calculated from the grid references of postcodes of the mother's address and of the units open at the time of the birth. The effect of distance was modelled using isotonic regression while adjusting for other factors (year of birth, paternal social class, and birth order). ${ }^{5}$ The isotonic model assumed that the risk of stillbirth did not decrease-that is, remained constant or increased-as the distance from the maternity services increased. Significance levels and tolerance bands were estimated by Monte Carlo simulation, ${ }^{5}$ assigning the 1234 stillbirths at random to the 79229 births and remodelling 100 times.

\section{Results}

The stillbirth rate fell significantly over the 40 year period of the study from 25 per 1000 births in the early 1950s to five per 1000 births in the late $1980 \mathrm{~s}$. The rate was significantly higher among less advantaged social classes, and it also varied significantly with birth order, the lowest risk being associated with second births.

Figure 1 shows the estimated isotonic functions that model the changing risk of stillbirth with distance from the nearest maternity services, together with 95\% tolerance bands, adjusted for year of birth, social class, and birth order. These functions remained virtually flat, except at large distances (over $25 \mathrm{~km}$ ) from hospitals, where there were few births, reflected in the wide tolerance bands. The overall test of the distance effects showed no significant increase in risk with increasing distance from either the first or second nearest maternity services $(\mathrm{p}=0.85,0.11$ respectively).

\section{Discussion}

The overall fall in stillbirth rate is similar to that seen in England and Wales over the same time period, where rates fell from 23.0 per 1000 births in 1950 to 4.7 per 1000 births in $1989 .{ }^{6}$ The rate in Cumbria has always been, and remains, slightly higher than that for the remainder of England and Wales. The increased risk we have observed with social class and the J shaped curve for risk with birth order are again consistent with other studies. ${ }^{6}$

Although births in the 1980 s tended to be at greater distances from maternity services than earlier births, as the result of the closure of small local maternity units, our results will be heavily influenced by the earlier decades of the study when the stillbirth rate was higher. Furthermore, obstetric practice was different then, with less routine antenatal care, a high proportion of home deliveries, and many deliveries in maternity units lacking consultant obstetric involvement. Nevertheless, they provide no evidence that living further from maternity services increased the risk of stillbirth. Thus the heterogeneity in stillbirth risk in Cumbria ${ }^{3}$ cannot be accounted for by differences in ease of access to both routine and emergency antenatal care as measured by distance from maternity services, nor can it be an explanation for the slightly higher rate of stillbirth in Cumbria relative to the remainder of England and Wales.

We thank Westlakes Research Institute for providing financial support for TMJ, the North of England Children's Cancer Research Fund for providing financial support for HOD and for the continuing support it gives to the Children's Cancer Research Unit at the University of Newcastle, and the Office for National Statistics for providing birth registration data.

1 Fikree FF, Midhet F, Sadruddin, S, Berendes HW. Maternal mortality in different Pakistani sites: ratios, clinical causes and determinants. Acta Obstet Gynecol Scand 1997;76:63745.

2 Jones AP, Bentham G. Health service accessibility and deaths from asthma in 401 local health authority districts in England and Wales, 1988-92. Thorax 1997;52:218-22.

3 Dummer TJB, Dickinson HO, Pearce MS, et al. Stillbirth rates around the nuclear installation at Sellafield, north west England: 1950-89. Int F Epidemiol 1998;27:74-82.

4 Parker L, Smith J, Dickinson H, et al. The creation of a database of children of workers at a nuclear facility: an exercise in record linkage. Applied Occupational and Environmental Hygiene 1997;12:40-5.

5 Diggle PJ, Morris SE, Morton-Jones AJ. Case-control regression for investigation of elevation in risk around a point source. Stat Med. [In press]

6 Office of Population Censuses and Surveys. Mortality statistics-perinatal and infant: social and biological factors (DH3, nos 7, 9, 13-15, 17, 18, 20-25). London: HMSO, 1978-1992. 